\title{
Phytotoxicity Assessment of Certain Phytochemical Products Containing Pyrrolizidine Alkaloids
}

\author{
Șeremet Oana Cristina1, Olaru OT², Ilie Mihaela3, Negreș Simona1', Bălălău D³ \\ 1 Department of Pharmacology and Clinical Pharmacy, Faculty of Pharmacy, "Carol Davila" University of Medicine and Pharmacy, Bucharest, Romania \\ 2 Department of Botany and Cellular Biology, Faculty of Pharmacy, "Carol Davila" University of Medicine and Pharmacy, Bucharest, Romania \\ 3 Department of Toxicology, Faculty of Pharmacy, "Carol Davila" University of Medicine and Pharmacy, Bucharest, Romania
}

\begin{abstract}
Introduction: Tussilago farfara (coltsfoot), Petasites hybridus (common butterbur), Senecio vernalis (eastern groundsel) and Symphytum officinale (comfrey) are species traditionally used in phytotherapy that besides the therapeutic compounds contain toxic pyrrolizidine alkaloids (PAs). The aim of the paper is to determine the total PAs content and the phytotoxicity of the above species.

Material and methods: The quantitative determination of pyrrolizidine alkaloids is based on the stoichiometric reaction of protonated alkaloids with methyl orange. In acidic conditions the dye is released from the complex and its color is assessed spectrophotometrically using a linear regression curve of senecionine as a standard. The phytotoxicity was assessed by Triticum bioassay that studies the effect of the extracts (0.001-5.00\%, w/v) upon root elongation (inhibitory concentration - IC50) and on the karyokinetic film.

Results: The highest amount of total PAs was found in Senecio vernalis $(654.8 \pm 35.96 \mu \mathrm{g} / \mathrm{g}$ dry plant) and the lowest in Petasites hybridus. The lowest IC50 was found for Tussilago farfara followed by Petasites hybridus, Senecio vernalis, and Symphytum officinale. The results were supported by microscopic examination.

Conclusions: The results of the spectrophotometric assay are consistent with the ones found in the literature. All extracts inhibited the elongation of the main root of wheat caryopses, however, no correlation between phytotoxicity and the PAs concentration could be emphasized.
\end{abstract}

Keywords: pyrrolizidine alkaloids, phytotoxicity, methyl orange

Received: 19 July 2013

\section{Introduction}

Tussilago farfara (coltsfoot), Petasites hybridus (common butterbur), Senecio vernalis (eastern groundsel) and Symphytum officinale (comfrey) are traditional phytotherapic species. Petasites hybridus root is used mainly for the antispastic, antiallergic and anti-inflammatory effects [1]. Tussilago farfara leaves are used to relief dry caught [2] and the aerial parts of Senecio species are used especially for their antidiarrheal, diuretic, diaphoretic and expectorant properties [3]. Symphytum officinale root in the form of compresses has healing properties for blunt injuries, varicose ulcers, burns and taken internally has been used to soothe ulcers [4].

Besides the therapeutic compounds these species contain toxic pyrrolizidine alkaloids (PAs) that are one of the most widely distributed natural toxins that affect wildlife, livestock and humans. Poisoning caused by these toxins is associated with acute and chronic liver damage and may be fatal [5]. Also, they possess mutagenic, genotoxic and teratogenic properties [6].

The PAs usually contain a base (necine), a bicyclic five atoms ring that bears 2 or more hydroxyl groups that are esterified with necic acids. The necines can be saturated or possess a double bond in the 1,2-position. The ones with a double bond in the $1,2-$ position are the toxic al- kaloids. The PAs can form N-oxides with the exception of the otonecines alkaloids (Figure 1) [5].

Several spectrophotometric methods have been described for the quantification of PAs. The most commonly used is that developed by Mattocks, that detects the 1, 2-unsaturated PAs and their $\mathrm{N}$-oxides (except for otonecine type PAs). The PAs are oxidized to the corresponding $\mathrm{N}$-oxides, dehydrogenated to pyrroles and coupled with 4-dimethylaminobenzaldehyde (Ehrlich's reagent) to form a magenta colored dye that can be measured spectrophotometrically at $563 \mathrm{~nm}[7,8]$. For the otonecine type PAs, Barko Bartkowski JP et al. developed a method in which the alkaloids react with acetylchloride and p-dimethyl-

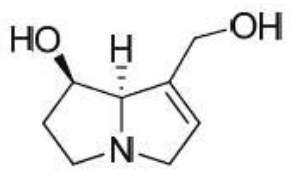

retronecine<smiles>CN1CC=C(CO)C(=O)[C@H](O)CC1</smiles>

otonecine

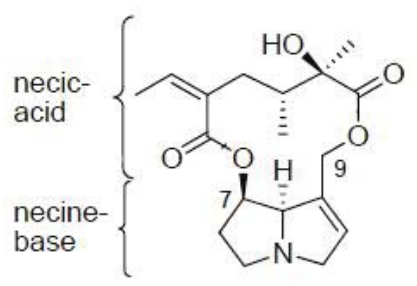

Fig. 1. Structural features of PAs [5] 
aminopyridine and generate a intermediate which forms a violet-blue dye with Ehrlich's reagent that can be measured spectrophotometrically at 590-600 nm [9].

Birecka $\mathrm{H}$ et al. describe an indirect method that is based on the protonation of PAs in a chloroformic solution with acetic acid and their stoichiometric reaction with aqueous methyl orange. A yellow complex highly soluble in chloroform is formed. Methyl orange is released from the complex in chloroform by ethanolic sulphuric acid after separation from the aqueous medium. The absorbance of the released methyl orange is measured at $525 \mathrm{~nm}$, being an indicative of the PAs concentration. The methyl orange method has a sensitivity comparable to that of Mattocks' method, is more rapid, and less expensive. It does not, however, allow one to distinguish unsaturated PA's from saturated ones [10].

Triticum test is a commonly used method for the assessment of cytotoxicity [11]. Along with other alternative toxicity methods using plants cells and invertebrates, this bioassay can be predictive for the genotoxicity of human cell.

The aim of the paper is to determine the total pyrrolizidine alkaloids (PAs) content and the phytotoxicity of the above species.

\section{Methods}

\section{Plant Material}

Coltsfoot and common butterbur teas (produced by Stef Mar Ltd., Valcea) and comfrey tea (produced by Fares, Orastie) were purchased from retail stores. S. vernalis aerial part was harvested in August 2012, from Deva Citadel (Hunedoara County), naturally dried and conserved in laboratory conditions. A voucher specimen is deposited at the Department of Botany, Faculty of Pharmacy, Carol Davila University of Medicine and Pharmacy, Bucharest, Romania.

The dried plants were pulverised (sieve $\mathrm{V}$ ) and $10 \mathrm{~g}$ were refluxed twice for $2 \mathrm{~h}$ with $1000 \mathrm{~mL}$ of $50 \%$ methanol acidified with citric acid to $\mathrm{pH} 2-3$. The combined extracts were stirred with $\mathrm{Zn}$ dust for $3 \mathrm{~h}$ at room temperature to convert PA-N-oxides to free PAs, evaporated to dryness under reduced pressure and dissolved in $50 \mathrm{ml}$ of distilled water.

The extractive solutions were coded as: SO (Symphytum officinale); PH (Petasites hybridus,); TF (Tussilago farfara); SV (Senecio vernalis).

For the spectrophotometric assay $25 \mathrm{~mL}$ of each extract was partitioned twice with chloroform, the organic layer was discarted, then twice with ether, the aqueous solutions were alkalinized with $25 \%$ ammonia ( $\mathrm{pH} 9-10)$; finally, the PAs, as free bases, were extracted by 3 -fold partition with chloroform, the combined organic layers were collected and combined, then evaporated to $1 \mathrm{~mL}$ on a concentration evaporator workstation, TurboVap 500 (Caliper, USA) and dried under nitrogen flow at room temperature
(Techne Dry-Block DB-3D, Bibby Scientific Inc., England). The residue was redissolved in $1 \mathrm{~mL}$ methanol and filtered through a $0.2 \mu \mathrm{m}$ syringe filter.

\section{Standard}

Senecionine (GC $\geq 95 \%$ ) was purchased from Carl Roth Germany and a $200 \mu \mathrm{g} / \mathrm{ml}$ standard solution in methanol was prepared. Standard working solutions with concentration between $5-40 \mu \mathrm{g} / \mathrm{ml}$ (obtained by diluting the stock solution with methanol), were used to obtain the calibration curve.

\section{Reagents}

Reagent I: $100 \mathrm{mg}$ methyl orange is dissolved in $20 \mathrm{ml}$ distilled water at $40^{\circ} \mathrm{C}$ for $20 \mathrm{~min}$, cooled to $20^{\circ} \mathrm{C}$ and filtered.

Reagent II: $1.25 \%$ aqueous acetic acid.

Reagent III: $0.5 \mathrm{ml}$ sulphuric acid is dissolved in $25 \mathrm{ml}$ absolute ethanol.

\section{Spectrophotometric assay}

The sample was evaporated to dryness and $5 \mathrm{~mL}$ of absolute ethanol followed by $10 \mu \mathrm{L}$ of reagent II were added. The solutions, in sealed vials, were mixed for 5 seconds, 25 $\mu \mathrm{L}$ reagent I was added and the mixing procedure was repeated for 10 seconds The phases were allowed to separate and $4 \mathrm{~mL}$ of the chloroformic phase was centrifuged at 400 $\mathrm{x} g$ for 2 minutes. To aliquots of $3 \mathrm{~mL}$ of the chloroformic phase, $0.3 \mathrm{~mL}$ reagent III is added. The absorbance was measured at $525 \mathrm{~nm}$ versus a blank prepared by duplicating the above procedure, but omitting the sample.

The measurements were performed on a UV-Vis Cary 100 Bio spectrophotometer (Varian Inc., USA). The spectra were recorded using $1 \mathrm{~cm}$ path lenght cell, in the range 400-700 nm, spectral bandwidth $1 \mathrm{~nm}$, scanning speed $600 \mathrm{~nm} / \mathrm{min}$.

All assays were performed in triplicate and the results were expressed as mean \pm standard deviation.

\section{Triticum bioassay}

The assessment of cytotoxicity through the Constantinescu method (Triticum test) was carried out by determining the maximal dilution of the extractive solutions which, depending on the time of action, influences the radicular elongation and the karyokinetic film [11].

Embryonic wheat roots (Triticum vulgare Mill, Boema cultivar, acquired from the SC Adaflor SRL, Zebil, Tulcea county) of $1 \mathrm{~cm}$ length have been maintained in Petri dishes (90 $\mathrm{mm}$ diameter), for 3 days in contact with the solutions to be analysed, each in concentrations of $5 \%, 1 \%$, $0.5 \%, 0.1 \%, 0.05 \%$ and $0.01 \%(\mathrm{w} / \mathrm{v})$, in a Sanyo MLR$351 \mathrm{H}$ germination room, at $25^{\circ} \mathrm{C}$ temperature, $75 \%$ relative humidity and in the absence of light. A control sample was prepared by replacing the extractive solutions with distilled water - M. The modifications of the karyokinetic film were observed after 24 hours on embryonic roots stained 
Table I. The total PAs content

\begin{tabular}{llc}
\hline No. Sample & $\begin{array}{c}\text { Total PAs content express in senecionine } \\
(\mu \mathrm{g} / \mathrm{g} \text { dry mass })\end{array}$ \\
\hline 1. & Symphytum officinale & $201.24 \pm 16.04$ \\
2. & Petasites hybridus & $59.61 \pm 0.22$ \\
3. & Tussilago farfara & $104.52 \pm 7.97$ \\
4. & Senecio vernalis & $654.83 \pm 35.96$ \\
\hline
\end{tabular}

with dilute acetic orcein solution, through microscopic examination using a Labophot 2 Nikon microscope (ocular 10x, ob. 40x, 100x) [11].

The inhibitory effect (Efi) of the two extractive solutions was calculated (in Excel 2003) in comparison to the control using the following equation:

$$
\mathrm{Ef}_{\mathrm{i}}=100-\frac{\mathrm{P}-1}{\mathrm{M}-1} 100
$$

where: $\mathrm{P}$ - sample average of the root elongation $(\mathrm{cm})$; $\mathrm{M}$ - control sample average of the root elongation $(\mathrm{cm})$; 1 - initial value of the embryonic roots $(\mathrm{cm}) ; 100-$ the results are expressed as a percentage

The inhibitory concentration (DI 50\%) represents the concentration at which root elongation is inhibited in 50\%.

Due to abnormal distribution of the values of the radicular elongation, for the statistical analysis of the results we used the Kruskal-Wallis test and the Dunn post-test, with a confidence interval of 95\% (CI 95\%) (GraphPadPrism software, v. 5.0).

\section{Results}

\section{Spectrophotometric assay}

A six points linear calibration curve of senecionine in the $0.91-7.27 \mu \mathrm{g} / \mathrm{ml}$ range with good linearity $(\mathrm{R} 2=0.9984)$ was obtained. The standard calibration curve and equation are presented in Figure 2.

Table II. The inhibitory effect (expressed as percentage) on the radicular elongation as compared to the control and the statistical significance

\begin{tabular}{|c|c|c|c|c|c|c|c|c|}
\hline \multirow[t]{2}{*}{ Vegetal product } & \multirow[t]{2}{*}{ Day } & \multirow[t]{2}{*}{ Statistical test } & \multicolumn{6}{|c|}{ Concentration } \\
\hline & & & $5 \%$ & $1.0 \%$ & $0.5 \%$ & $0.1 \%$ & $0.05 \%$ & $0.01 \%$ \\
\hline \multirow[t]{9}{*}{ so } & 1 & Efi (\%) & 100 & 98.29 & 91.44 & 24.32 & 25.68 & 12.33 \\
\hline & & Dunn & $\star \star \star *$ & $* * *$ & 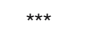 & ns & ns & ns \\
\hline & & Kruskal Wallis & \multicolumn{6}{|c|}{ 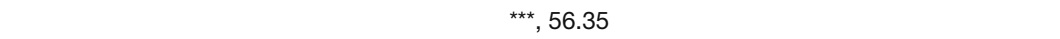 } \\
\hline & 2 & Efi (\%) & 100 & 99.48 & 95.35 & 23.24 & 31.33 & 19.97 \\
\hline & & Dunn & $\star \star \star ~$ & $* * *$ & 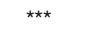 & ns & ns & ns \\
\hline & & Kruskal Wallis & \multicolumn{6}{|c|}{$\star * \star \star, 58.20$} \\
\hline & 3 & Efi (\%) & 99.64 & 98.31 & 95.52 & 40.07 & 41.53 & 18.89 \\
\hline & & Dunn & *** & 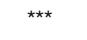 & 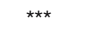 & ns & ns & ns \\
\hline & & Kruskal Wallis & \multicolumn{6}{|c|}{${ }^{\star * \star}, 60.94$} \\
\hline \multirow[t]{9}{*}{$\mathrm{PH}$} & 1 & Efi (\%) & 99.31 & 100 & 100 & 83.56 & 86.98 & 20.20 \\
\hline & & Dunn & 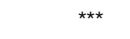 & 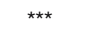 & $\star \star \star \star ~$ & $\star \star$ & * & ns \\
\hline & & Kruskal Wallis & \multicolumn{6}{|c|}{ 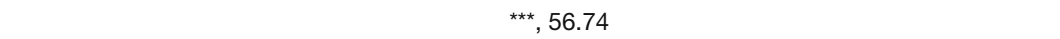 } \\
\hline & 2 & Efi (\%) & 99.48 & 100 & 100 & 89.50 & 86.74 & 7.40 \\
\hline & & Dunn & 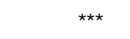 & 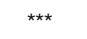 & 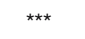 & $\star *$ & * & ns \\
\hline & & Kruskal Wallis & \multicolumn{6}{|c|}{${ }^{\star \star \star}, 56.78$} \\
\hline & 3 & Efi (\%) & 98.91 & 98.91 & 99.51 & 89.34 & 98.22 & 9.68 \\
\hline & & Dunn & $* \star \star$ & 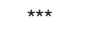 & 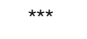 & ns & * & ns \\
\hline & & Kruskal Wallis & \multicolumn{6}{|c|}{${ }^{\star \star \star}, 57.09$} \\
\hline \multirow[t]{9}{*}{ TF } & 1 & Efi (\%) & 100 & 100 & 96.57 & 86.64 & 66.78 & 40.12 \\
\hline & & Dunn & 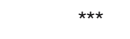 & $\star \star \star \star ~$ & $\star \star \star \star ~$ & * & ns & ns \\
\hline & & Kruskal Wallis & ${ }^{* \star \star}, 64.77$ & & & & & \\
\hline & 2 & Efi (\%) & 100 & 100 & 98.62 & 91.22 & 74.52 & 43.61 \\
\hline & & Dunn & $* \star \star *$ & $* \star *$ & 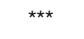 & ** & ns & ns \\
\hline & & Kruskal Wallis & ${ }^{* \star \star}, 65.42$ & & & & & \\
\hline & 3 & Efi $(\%)$ & 100 & 100 & 99.27 & 93.46 & 72.51 & 34.16 \\
\hline & & Dunn & $\star \star \star *$ & $\star \star \star *$ & 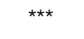 & ** & ns & ns \\
\hline & & Kruskal Wallis & ${ }^{\star \star \star \star}, 66.26$ & & & & & \\
\hline \multirow[t]{9}{*}{ SV } & 1 & Efi (\%) & 99.65 & 99.31 & 95.20 & 83.90 & 69.52 & 16.78 \\
\hline & & Dunn & 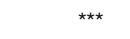 & $\star \star \star *$ & 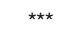 & * & ns & ns \\
\hline & & Kruskal Wallis & \multicolumn{6}{|c|}{ 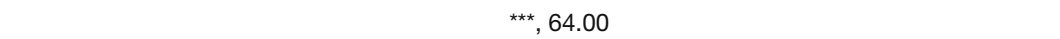 } \\
\hline & 2 & Efi (\%) & 99.82 & 99.65 & 98.45 & 86.57 & 63.85 & 1.37 \\
\hline & & Dunn & 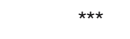 & 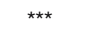 & 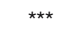 & ** & ns & ns \\
\hline & & Kruskal Wallis & \multicolumn{6}{|c|}{$* \star \star, 65.42$} \\
\hline & 3 & Efi (\%) & 99.87 & 98.78 & 98.42 & 82.20 & 68.64 & 4.84 \\
\hline & & Dunn & $* \star *$ & $* \star \star$ & $\star \star \star *$ & * & ns & ns \\
\hline & & Kruskal Wallis & \multicolumn{6}{|c|}{ 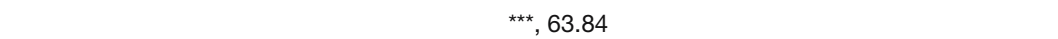 } \\
\hline
\end{tabular}




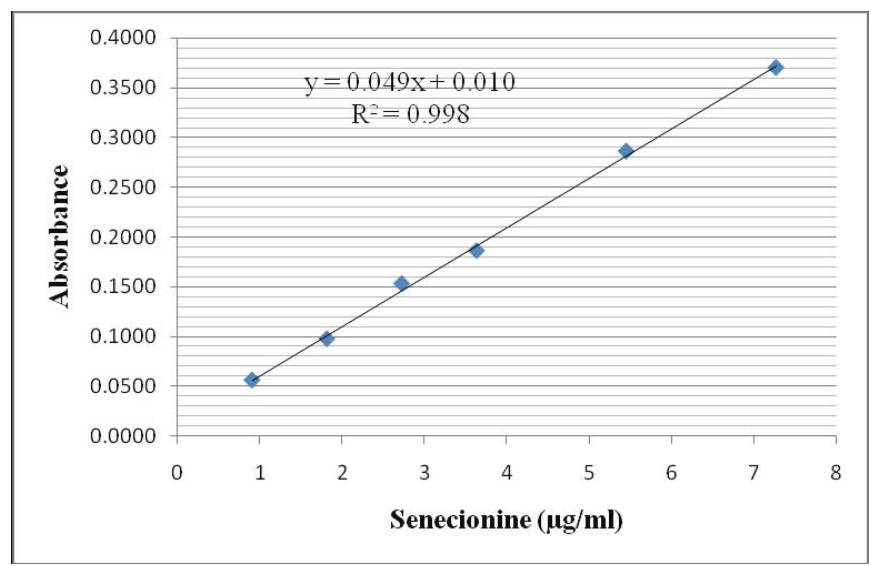

Fig. 2. The standard calibration curve and equation for senecionine

The total PAs content for the 4 vegetal products is summarized in Table I.

\section{Triticum bioassay}

Table II presents the inhibitory effects (expressed as percentage) of the analysed solutions on the radicular elongation as compared to the control and the statistical significance during the 3 testing days. The inhibitory doses were calculated for each solution during the period of experiment (Table III).

The microscopic examination revealed that TF at highest concentration showed cytotoxic activity (no cell division was observed). $\mathrm{PH}, \mathrm{SO}$ and $\mathrm{SV}$ were toxic for cell division leading to abnormal divisions (hypertrophied nuclei with abnormal shapes, metaphases and anaphases in tropokinesis, disorganized metaphases). Division toxicity is dose dependent at all extracts. Even at $0.01 \%$ was observed abnormal divisions (metaphases in tropokinesis) and numerous normal cell division (karyokinetic film without changes).

\section{Discussions}

The highest amount of the total PAs was determined in the extract of Senecio vernalis $(654.83 \pm 35.96 \mu \mathrm{g} / \mathrm{g}$ dry mass) followed by Symphytum officinale $(201.24 \pm 16.04$ $\mu \mathrm{g} / \mathrm{g}$ dry mass). The lowest amount of total PAs was found in Petasites hybridus extract $(59.61 \pm 0.22 \mu \mathrm{g} / \mathrm{g}$ dry mass). The results of the spectrophotometric assay are consistent with the ones found in the literature $[5,12,13]$.

All the tested solutions inhibit at high concentrations $(0.5-5 \%)$ over $90 \%$ the root elongation (statistically significant differences). For SO at $0.01-0.1 \%$ Efi is between $12.33-40.07 \%$, which is not supported statistically. The other extracts inhibit the root elongation at $0.05-0.01 \%$ between $63.85-93.46 \%$ (statistically significant). At $0.01 \%$ concentration all the extracts inhibit between 1.37 $-40.12 \%$, but the results were comparable to the control in terms of statistics. The lowest inhibitory concentration was
Table III. The values of inhibitory doses (DI50\%), the regression ecuations and the coefficient of determination

\begin{tabular}{lcccc}
\hline Extract & Day & Regression equation & $\mathrm{r} 2$ & DI50\% $(\mu \mathrm{g} / \mathrm{mL})$ \\
\hline SO & 1 & $y=39.93 x+84.65$ & 0.8609 & 0.1355 \\
& 2 & $y=37.51 x+85.96$ & 0.8152 & 0.1099 \\
& 3 & $y=34.92 x+88.38$ & 0.8830 & 0.0796 \\
PH & 1 & $y=25.56 x+98.30$ & 0.8263 & 0.0128 \\
& 2 & $y=28.85 x+99.29$ & 0.7679 & 0.0195 \\
& 3 & $y=27.52 x+98.84$ & 0.7250 & 0.0168 \\
TF & 1 & $y=29.22 x+96.69$ & 0.6451 & 0.0085 \\
& 2 & $y=20.24 x+97.76$ & 0.5984 & 0.0042 \\
& 3 & $y=21.43 x+98.08$ & 0.5776 & 0.0080 \\
SV & 1 & $y=28.56 x+95.98$ & 0.7612 & 0.0245 \\
& 2 & $y=33.87 x+96.99$ & 0.7285 & 0.0410 \\
& 3 & $y=32.44 x+96.57$ & 0.7382 & 0.0367 \\
\hline
\end{tabular}

obtained for TF $(0.0042 \mu \mathrm{g} / \mathrm{ml})$ followed by PH $(0.0128$ $\mu \mathrm{g} / \mathrm{ml}), \mathrm{SV}(0.0245 \mu \mathrm{g} / \mathrm{ml})$ and $\mathrm{SO}(0.0796 \mu \mathrm{g} / \mathrm{ml})$. The results were supported by microscopic examination.

\section{Conclusions}

All extracts inhibited the elongation of the main root of wheat caryopses, however, no correlation between phytotoxicity and the PAs concentration could be emphasized. The inhibitor effect is probably due to other active principles of vegetable extracts.

\section{References}

1. Fliebich BL, Grozdeva M, Hess S, et al. Petasites hybridus extracts in vitro inhibit COX-2 and PGE2 release by direct interaction with the enzyme and by preventing $\mathrm{p} 42 / 44 \mathrm{MAP}$ kinase activation in rat primary microglial cells. Planta Med. 2005;71:12-19.

2. ${ }^{\star \star *}$ PDR for Herbal Medicines, Third Edition, Thompson PDR, Montvale, 2004, 220-221

3. Mogoșanu GD, Pintea A, Bejenaru LE, et al. HPLC analysis of carotenoids from Senecio vernalis and S. jacobaea (Asteraceae). Farmacia. 2009;57(6): 780-786.

4. ${ }^{\star \star \star}$ Committee on Herbal Medicinal Products (HMPC). Assessment report on Symphytum officinale L., radix (EMA/HMPC/572844/2009), 2011

5. ${ }^{* *}$ Scientific Opinion on Pyrrolizidine alkaloids in food and feed. EFSA Journal. 2011;9:2406-2540.

6. Roeder E. Medicinal plants in Europe containing pyrrolizidine alkaloids. Pharmazie. 1995;50:83-98.

7. Mattocks AR. Spectrophotometric determination of unsaturated pyrrolizidine alkaloids. Anal. Chem. 1967;39:443-447.

8. Mattocks AR. Spectrophotometric determination of pyrrolizidine alkaloidssome improvements. Anal. Chem. 1968;40:1749-1750.

9. Barko Bartkowski JP, Wiedenfeld H, Roeder E. Quantitative Photometric Determination of Senkirkine in Farfarae Folium. Phytochem. Anal. 1997;8: $1-8$

10. Birecka $H$, Catalfamo JL, Eisen RN. A sensitive method for detection and quantitative determination of pyrrolizidine alkaloids. Phytochemistry. 1981;20:343-344.

11. Ancuceanu R, Istudor V, Dinu M, Codreanu M. Contribution to the study of some Cuscuta species. Note 2. Use of the Constantinescu bioassay in the study of the correlations between Cuscuta sp. and their hosts. Farmacia. 2005;53:63-75.

12. Couet CE, Crews C, Hanley AB. Analysis, separation, and bioassay of pyrrolizidine alkaloids from comfrey (Symphytum officinale). Nat Toxins. 1996;4:163-167.

13. Wildi E, Langer T, Schaffner W, Büter KB. Quantitative analysis of petasin and pyrrolizidine alkaloids in leaves and rhizomes of in situ grown Petasites hybridus plants. Planta Med. 1998;64:264-267. 